\title{
(Con)Textos na linha de produção
}

\author{
(Con) Texts in the production line
}

\section{Elaine Teixeira da Silva ${ }^{1}$}

1 Especialista em Ensino de Língua Espanhola pela Universidade Candido Mendes, Especialista em Estudos de Língua Portuguesa e de Literatura Brasileira pelo Centro Universitário São José de Itaperuna, Licenciada Letras em Português / Espanhol pelo Centro Universitário São José de Itaperuna, Brasil. E-mail: elaine.ts@gmail.com

Todos nós estamos "em busca do texto perfeito" tanto como leitores quanto escritores de suas ideias em forma de palavras e a intenção do autor é fazer com que o leitor embarque em uma viagem traçada pelas construções imaginárias descritas em forma de letras, vírgulas, pontos, etc.

0 processo para que um livro em mãos seja o mais atrativo e impressionante para quem o lê não é tão simples e não está somente a cargo de quem o escreve - o autor. Ele passa também pelo revisor, pelo editor e pelo diagramador. Mas alguns questionamentos são feitos para que se chegue ao "texto perfeito":

Quem são, atualmente, esses preparadores e revisores? Com que qualificação eles atuam? Que orientações seguem e que tipo de intervenção fazem no texto? Que interação ocorre entre esses profissionais e os autores dos textos em que intervêm? Quanto de professor há no revisor (e vice-versa)? Preparador, revisor, corretor e professor? (RIBEIRO, 2016, p. 68 - 69).

Essas são algumas das questões que a autora Ana Elisa Ribeiro (2016) busca responder em uma "boa conversa" (RIBEIRO, 2016, p. 12), como a própria autora faz questão de mencionar, nas 136 páginas do livro "Em busca do texto perfeito: questões contemporâneas de edição, preparação e revisão textual", uma reunião de trabalhos feitos por ela sobre o tema título da obra.
Figura 1: Capa do livro Em busca do texto perfeito: questões contemporâneas de edição, preparação e revisão textual.

Figure 1: Book cover Em busca do texto perfeito: questões contemporâneas de edição, preparação e revisão textual.

ANA ELISA RIBEIRO

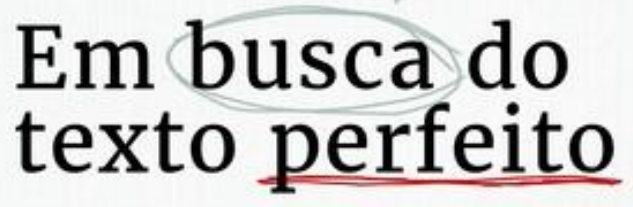

\section{Questões contemporâneas de edição,} preparação e revisão textual.

Fonte: <http://gullivereditora.com.br/?product=em-busca-dotexto-perfeito>

Ao abordar o tema, Ribeiro (2016) traz alguns autores que de forma direta ou indireta descrevem os profissionais que se em- 
penham na produção total e final de uma publicação seja ela impressa ou no meio digital como temos nos dias atuais com os e-books.

A obra é composta por cinco capítulos, sendo as "Considerações iniciais ou Isto não é um manual" a responsável por trazer ao leitor a noção do que ele encontrará nas páginas seguintes, a começar pela formação, apresentando autores, dos poucos que abordam o assunto em questão, como o historiador Roger Cartier e análises sobre 0 "cronista prescritivista" (RIBEIRO, 2016, p. 50) mineiro Eduardo Almeida Reis.

No capítulo 1 "(In)distinções dentre as atividades do preparador e do revisor de provas na produção de livros", a autora aborda as questões relacionadas à formação dos "profissionais competentes para lidar com textos" (RIBEIRO, 2016, p. 14), ficando a cargo dos cursos de Letras e de Comunicação Social, já que elas formam sujeitos que estarão ligados ao texto em suas diferentes formas. Contudo, há fatores que apontam a defasagem das disciplinas ofertadas nesses cursos com relação ao sujeito que trabalhará com a produção, edição e revisão textual incentivando ao graduando e até mesmo aos já graduados dessas disciplinas à reflexão sobre o papel dos profissionais que desejam se embrenhar no ramo da produção dos textos.

Desse modo,

Pensamos ser absolutamente necessário investigar quais competências esse profissional precisa desenvolver, ao longo de sua formação universitária, para compreender sua atuação real e sua inserção no mundo da produção editorial, seja ela gráfica ou digital (RIBEIRO, 2016, p. 16).

O cap. 2, "Representações do revisor de textos", a autora aborda a questão gramatical dentro da linha de produção textual, trazendo conceitos segundo alguns gramáticos como Carlos Alberto Faraco, Dante Lucchesi e Marcos Bagno.

Junto aos gramáticos está o cronista mineiro Eduardo Almeida Reis que nas crônicas apresentadas mostra-se como um sujeito que insere o leitor ao mundo da linguagem com o seu rico vocabulário, mas também como um crítico direto ao seu revisor, pois: "'Ferir o coração da língua portuguesa' é sinônimo de um erro de revisão, não erro do autor, claro" (RIBEIRO, 2016, p. 55).

Ainda neste capítulo, há indicações de leituras sobre o tema. Autores literários que mencionam os profissionais do texto em suas obras, como José Saramago e Clarice Lispector, indicações de filmes, blogues, matérias jornalísticas e obras dos linguistas Marcos Bagno, Luiz Percival Leme Brito e João Wanderley Geraldi.

No cap. 3, "Revisão de textos e 'diálogos' com o autor: abordagens profissionais do processo de produção e edição textual", Ribeiro considera "a revisão e a preparação de textos como 'fases' distintas da etapa da produção editorial" (RIBEIRO, 2016, p. 63).

Apoiando-se em Chartier, a autora apresenta a distinção entre o papel do autor e do revisor desde o século $\mathrm{XVI}$ até o século $X X I$, abordando mais uma vez a formação do profissional em especial ao do professor de língua materna na função de revisor e da formação em Comunicação Social como profissional de edição.

Encontramos também o fator do diálogo que existe entre quem escreve e quem o revisa levantando a questão de que "Até que ponto se pode 'mexer em um texto"'? (RIBEIRO, 2016, p. 70), buscando sempre corroborar as suas observações a de outros 
pesquisadores.

Ribeiro mostra exemplo em que a intervenção do revisor pode alterar "profundamente o dizer dos autores" (RIBEIRO, 2016, p. 74) quando não há o diálogo, como também exemplos em que o editor atua como um conselheiro do autor, ficando a cargo deste as alterações no texto podendo acatar ou não as sugestões daquele, quando o diálogo acontece por intermédio de uma ferramenta do Word.

Para encerrar o capítulo, a autora traz indicação "bibliográfica brasileira sobre a revisão de textos" (RIBEIRO, 2016, p. 76), além de dar dicas de qual deve ser o papel do revisor frente aos textos de registro formal ou não, pois segunda ela o revisor precisa "ser íntimo das linguagens, dos gêneros textuais e da vivacidade da língua, em suas performances" (RIBEIRO, 2016, p. 76).

O penúltimo capítulo, "Escrevendo as horas: usos e convenções de uma abreviatura", aborda os usos e convenções de uma abreviação, as horas. Perpassando pelas normas e usos expressos em manuais, dicionários e gramáticas, a autora apresenta uma atividade realizada com alunos abordando as ocorrências de abreviatura da palavra hora, levando os estudantes a refletirem "sobre os usos, os porquês dos usos e a consulta aos manuais, no que eles têm de consenso e, principalmente, no que têm de dissenso" (RIBEIRO, 2016, p. 96).

O quinto e último capítulo, "Relações virtuais, edições de papel e a renovação da literatura brasileira", descreve o processo evolutivo da edição e dos "novos autores" (RIBEIRO, 2016, p. 101)e a relação entre autor e editor com a chegada das novas tecnologias da informação e comunicação que possibilita a realização dos trabalhos editoriais mesmo que ambos estejam sepa- rados geograficamente com uma "correspondência eletrônica" (RIBEIRO, 2016, p. 103) que "aqui mostrada ainda operam com um uma lógica clássica de produção, edição, marketing e distribuição" (RIBEIRO, 2016, p. 103). Além de mostrar que a evolução advinda com as Novas Tecnologias Digitais da Informação e Comunicação (NTDIC) abriram caminho para uma escrita colaborativa no suporte virtual, como o Google Drive ou com wikis em que vários autores e editores inserem suas escritas, observações e correções.

A autora termina o capítulo oferecendo uma lista de livros e filmes "baseados em livros, filmes e livros sobre personagens da edição, etc." (RIBEIRO, 2016, p. 121), além de sugerir que a discussão sobre o tema editorial apenas começou.

Em tempo de "modernidade diluída" (BAUMAN, 2013, p. 69), tema como esse precisa ser analisado com atenção, pois as NTDIC aproximaram distâncias geográficas e espaciais entre autor, editor, revisor, editora, mas também trouxe a questão da divulgação de obras sem autorização de editoras, o plágio, as citações sem as devidas referências entre outras questões que merecem uma nova análise científica.

\section{REFERÊNCIAS}

BAUMAN, Z. Sobre educação e juventude: conversas com Ricardo Mazzeo. Rio de Janeiro: Zahar, 2013.

RIBEIRO, A. E. Em busca do texto perfeito: questões contemporâneas de edição, preparação e revisão textual. Divinópolis, MG: Artigo A, 2016.

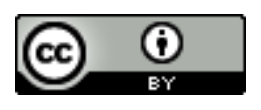
License information: This is an open- 
access article distributed under the terms of the Creative Commons Attribution License, which permits unrestricted use, distribution, and reproduction in any medium, provided the original work is properly cited.

Artigo recebido em 05 de agosto de 2017.

Avaliado em 20 de outubro de 2017.

Aceito em 23 de outubro de 2017.

Publicado em 19 de dezembro de 2017.

\section{Como citar este artigo (ABNT):}

SILVA, Elaine Teixeira da. (Con)Textos na linha de produção. Estação Científica (UNIFAP), Macapá, v. 7, n. 3, p. 119-122, set./dez. 2017. 